\title{
An attributional Life Cycle Assessment application experience to highlight environmental hotspots in the production of foamy polylactic acid trays for fresh-food packaging usage
}

\author{
Carlo Ingrao ${ }^{a, *}$, Matteo Gigli $^{\text {b }}$, Valentina Siracusa ${ }^{\text {a }}$ \\ a. Department of Chemical Science, University of Catania, Viale A. Doria 6, Catania 95125, Italy \\ b. Department of Chemical Science and Technologies, University of Roma Tor Vergata, Via della Ricerca \\ Scientifica 1, 00133 Roma, Italy \\ * Corresponding author: ing.carloingrao@gmail.com
}

\begin{abstract}
Food packaging systems mainly serve to contain and protect foods during their shelf-lives. However, it is well known that a package is responsible for several environmental impacts associated with its entire life-cycle. Therefore, package design should be developed taking into account not only cost, food shelf-life and safety, as well as user-friendliness, but also environmental sustainability. To address and improve this latter issue, environmental evaluation methodologies need to be applied: Life Cycle Assessment is one amongst them, and can be considered a valid tool for this purpose. Indeed, it has been long applied in the food packaging field to highlight both environmental hotspots and improvement potentials for more eco-friendly products.

In this context, this paper reports upon a Life Cycle Assessment application experience in the production of foamy Polylactic Acid (PLA) trays for fresh-food packaging applications.

The study highlighted that the highest environmental impacts come from the production and transport of the granules, so remarking the need to search for alternative biopolymers. In this regard, the results of this study will form the base for another one regarding the assessment of second-generation PLA granules, namely those produced by processing both wastes and wastewaters from starchy crop cultivation systems and processing plants.
\end{abstract}

\section{Keywords}

Food packaging

Biopolymers

Polylactic acid

Tray

Life Cycle Assessment

Environmental hotspots 


\section{Introduction}

In 2015, the global plastic market reached 322 Mtons, 58 of which have been produced in Europe (PlasticsEurope, 2016). A significant portion of the total european plastic demand (about $40 \%$ of 49 Mtons) is employed for packaging purposes, whilst other sectors include building and construction (20\%), automotive (9\%) and electrical and electronic (6\%) (PlasticsEurope, 2016).

The huge employment of polymers in the packaging sector is due to a combination of several favourable factors such as light weight, flexibility, strength, transparency, impermeability and ease of sterilisation (Siracusa et al., 2008).

This massive consumption of polymeric materials is accompanied by a consistent waste generation that causes several environmental pollution problems. Plastics are mainly produced for durable scopes and, therefore, can persist un-degraded for decades in the environment where they are disposed. In particular, the marine litter issue has raised great environmental concern since it is harmful to ocean ecosystems, wildlife, and humans. Besides cigarette residues, food wrappers/containers, plastic bags, beverage plastic bottles and plastic cutlery are the most important sources of debris (Marine Litter Solutions, 2016). A recent study from Jambeck et al. (2015) indicated that, only in 2010, 4.8 to 12.7 Mtons of plastics ended up in the oceans.

Waste production and management is currently one of the main focuses of the environmental strategies and policies that have been developed thus far at international and European level. To date, the European Union has promoted a number of industry regulations with the aim of both pursuing environmental objectives and preventing possible risks to human health, and introducing numerous innovations in the classification of wastes as well as in the ways adoptable for their recovery and/or disposal. In this regard, it is now widely accepted that waste management policies should not rely only upon the traditional form of landfill disposals, but should also be focussed upon integrated strategies (Messineo et al., 2012) that provide both development and optimisation of separate-municipal-collection systems, and more environmentally sustainable disposal scenarios. In the field of plastic materials and finished-products, recycling would be a more favourable disposal scenario to be pursued (Rossi et al., 2015). In particular, Michaud et al. (2010) reviewed several types of plastic wastes and the environmental performances of their disposal scenarios, namely recycling, incineration (with energy recovery) and landfill, considering the following environmental impact indicators: 'Climate change potential', 'Depletion of natural resources', 'Energy demand', 'Acidification', 'Photochemical oxidation', 'Eutrophication', and 'Human toxicity'. They documented that, on an average basis, mechanical recycling is the most environmentally sustainable option for plastic waste treatment as it performs best in almost all of those indicators. This should be attributed to the avoided production of virgin plastics generating, in turn, avoided environmental impacts, and maximised by collection of good quality material and replacement of virgin plastics on a high ratio (1 to 1). Additionally, in their review report, Michaud et al. (2010) highlighted that, for all those environmental impact indicators, incineration (with energy recovery) can be considered on an average basis as the intermediary option, whilst landfill is confirmed as having the worst environmental performance.

Despite of this, yet above 30\% of plastic wastes were land-filled in 2014 (PlasticsEurope, 2016). Moreover, recycling is not always a viable option. This is the case of food packaging, which cannot 
be recycled due to oganic substances contamination, and composting remains therefore the only alternative to landfilling (Kale et al., 2007).

In this framework, the growing environmental awareness imposes also eco-friendly attributes to packaging products and processes. Amongst other possibilities, the use of biopolymers (i.e. biobased polymers and/or biodegradable polymers) for the realisation of sustainable food packaging offers several advantages.

The development of materials with biodegradability and/or compostability attributes would in fact significantly reduce the municipal solid waste (Peelman et al., 2013). Water and enzymes produced by microorganisms are firstly responsible of the polymer breakdown to low molecular weight intermediates, which are taken up by the microbial cells to be finally converted into water, carbon dioxide and biomass (Grima et al., 2002; Gigli et al., 2013; Genovese et al., 2014). On the other hand, the exploitation of renewable resources for the synthesis of polymeric materials would lower the consumption of and so dependence upon fossil fuels, although it was reported that, at least in Europe, only 4-6\% of the oil and gas production is utilised for plastic production (PlasticsEurope, 2016). It is also worth highlighting that consumers and producers have recently become more sensitive towards environmental issues, and it is consolidated that packaging plays an important role in the overall sustainability of food productions (Licciardello et al., 2014)

Among other characteristics, food packaging mainly needs to guarantee food conservation and preservation for long periods, reducing at the same time waste and utilisation of preservatives. Therefore, the selection of packaging systems by food producers should consider both effectiveness, i.e. the ability to maintain quality through shelf life, and efficiency, meant as the containment of environmental impact and costs generated by packaging production and disposal (Licciardello et al., 2017).

To date, due to these strict requirements, not many biopolymers have been successfully employed for food packaging, most common being aliphatic polyesters (above all polylactic acid), starch and cellulose (Peelman et al., 2013).

In this context, Polylactic Acid (PLA) is a family of bio-based and biodegradable thermoplastic aliphatic polyesters. Whilst in the past it has been mostly used for biomedical applications because of the high cost and poor availability (Castro-Aguirre et al., 2016), PLA is recently growing as a greener alternative to conventional packaging. PLA has already received the Food and Drug Administration (FDA) approval for food-contact applications (Ahmed and Varshney, 2011), which makes it usable for food-packaging applications. As a matter of fact, it is currently used to realise short shelf-life food packaging such as trays, drinking cups, sundae and salad cups, over-wrap and lamination films, and blister packages (Ahmed and Varshney, 2011).

Large scale productions of PLA started in 2003 under the trade-name Ingeo by NatureWorks LLC (Natureworks, 2016). Today, Ingeo is produced with a capacity of 150 Mtons a year by ROP of lactide (Castro-Aguirre et al., 2016). The lactic acid raw material can be obtained either by chemical synthesis or by bacterial fermentation, this last being the preferred option by the two main PLA industrial producers, i.e. Natureworks LLC and Corbion.

A detailed description of PLA production, properties and processing falls beyond the scope of this paper, and comprehensive reviews on this topic have been recently published and can be found in the literature (Castro-Aguirre et al., 2016; Chen et al., 2016). 
The increasing utilisation of PLA in the food packaging field makes it important and useful to develop studies for the assessment of both environmental impacts and improvement potentials in the lifecycle of PLA-based food packaging products. Several tools and methods are currently available for this purpose: Life Cycle Assessment (LCA) is acknowledged globally to be a valid one.

In this context, the study discussed in this paper regards application of LCA of fresh-food packaging trays made out of PLA with the aim of understanding their effective impacts on the environment as the starting base for the greening of their supply chains.

\section{Environmental assessment in the food packaging field: a literature review}

This section provides a brief overview of the most recent publications in the field of LCA assessment of food packaging with a particular focus upon bio-polymeric systems.

Indeed, as reported by Verghese et al. (2012) it is of key importance that LCA shifts from a reflective to an action-oriented decision-making tool, in order to aid packaging designers and producers to reduce the environmental impact of their products.

In an interesting study, 12 polymers (7 obtained from fossil fuels, 4 from renewable resources and one from both) were compared with respect to their environmental impacts (Tabone et al., 2010). In addition, their adherence to green design principles was assessed by Tabone et al. (2010). Interestingly, the authors of that paper observed that the obedience to green principles contributes to reduce the environmental impact of either petroleum polymers and biopolymers. However, it should be observed that, as stated by Tabone et al. (2010), the employment of renewable resources instead of fossil feedstocks does not necessarily allows for reduction of the related environmental impacts.

A recent work from Yates and Barlow (2013) reviewed and compared LCA reports on polylactic acid, polyhydroxyalcanoates and starch-based polymers coming to a similar conclusion. The authors underlined also that LCAs made on the same product and Functional Unit (FU) sometimes led to different conclusions due to discrepancies in the assumptions made about system boundaries and allocation methods making a direct comparison more difficult (Yates and Barlow, 2013).

More specific life-cycle assessments on food packaging are also present in the literature and will be mentioned in the following.

Different packaging systems for the transport of fruits and vegetables across Europe have been evaluated (Albrecht et al., 2013). Single-use wooden and cardboard boxes and reusable plastic crates have been analysed and compared considering environmental, social and economic impacts. The results outlined that wooden boxes and plastic crates have similar impacts with regards to global warming, acidification, and photochemical ozone creation potential categories. On the other hand, plastic crates perform better with respect to eutrophication and abiotic resource depletion potentials. Lastly, cardboard boxes display the highest impact in all the assessed categories. Moreover, the plastic system is the most cost effective over its entire life-cycle and shows a much lower lethal accident rate. In conclusion, the work highlighted the importance of including also economic and social dimensions when performing LCAs to ensure a more comprehensive approach (Albrecht et al., 2013). 
Similarly, in a recent work by Bernstad Saraiva et al. (2016), mango packaging realised from $\mathrm{PE} /$ natural fiber composites or cardboard have been studied through a life cycle assessment approach. The authors developed two different scenarios, assuming their use in Brazil and in Europe. When single use was considered, the cardboard tray resulted less impacting for almost all the considered categories, because of the higher weight of the composite packaging, which caused a higher fuel consumption for transportation and a higher electricity imput. On the other hand, the impact of the composite trays was lower than that of cardboard packaging after 4 reuses for the Brazilian scenario and 29-35 for the European one. This discrepancy can be largely imputed to the different end of life treatment in Brazil and Europe (Bernstad Saraiva et al., 2016).

Another paper by Wikström et al. (2016) demonstrated that indirect environmental effects and user behavior should be included when performing environmental assessment of food packaging. Indeed, the authors studied the impact of two different packages for minced meat: lightweight tube and tray, and considered direct and indirect environmental effects for the LCA analysis (Wikström et al., 2016). The lightweight tube was a better alternative when only direct effects were examined. On the contrary, the inclusion of the user behavior and indirect effects resulted in an opposite output, largely because of the less food waste during the tray emptying (Wikström et al., 2016). As stated by Siracusa et al. (2014), one of the first LCA analyses on food packaging compared the production of polystyrene (PS) six-egg packages with those obtained from recycled paper and was carried out by Zabaniotou and Kassidi (2003). Although not fully developed, LCA was already considered at that time a useful tool to assist and guide product development and environmental comparative assessment of different items. Since then, the LCA technique considerably evolved and lots of authors produced interesting pieces of work on the food packaging topic, as recently reviewed by Siracusa et al. (2014) and Ingrao et al. (2015c).

As to the biodegradable food packaging, it is worth mentioning the work of Vidal et al. (2007) that compared a biodegradable multilayer film based on modified starch and PLA with conventional multilayer film based on polypropylene (PP) and polyamide- 6 with respect to climate change, fossil fuel depletion, acidification and eutrophication. According to the authors, conventional packaging displays a $90 \%$ higher impact than the biodegradable one (Vidal et al., 2007).

In another interesting contribution by Madival et al. (2009), thermoformed clamshells made out of PS, PLA and PET for the packaging of strawberries have been examined through a cradle-to-cradle LCA approach. Results demonstrated that PET had the highest impact in almost all the considered categories, mainly because of the higher weight of the containers. In addition, the authors found out that the transportation stage was the major contribution to the global warming, ozone layer depletion and aquatic ecotoxity categories for all three polymers studied (Madival et al., 2009). The environmental impact of bio-based wrappings (bio-PE, PLA and paper) and conventional ones (PP and PE) was evaluated by Hermann et al. (2010). The authors reported that bio-PE and paper/PLA laminates offer significant impact reduction with respect to the current materials, particularly when used as outer packaging because of the less strict requirements in terms of barrier properties.

From an analysis of the environmental performance of sugar-cane bagasse food trays in comparison with PE, PET and PLA trays emerged that the first one show the lowest impact for non-renewable 
energy use, global warming, abiotic depletion and acidification, while PET displays the highest impact for the same indicators (Roes and Patel, 2011).

Suwanmanee et al. (2013) reported an LCA evaluation of polystyrene (PS), PLA and PLA/cassava starch blend (PLA/starch) single use thermoform boxes. In this work a slightly higher environmental impact has been observed for PLA and PLA/starch trays with respect to PS (1.59 and 1.09 times, respectively) when indirect land use change (LUC) is excluded. For contrast, their impact considerably increases when LUC emission is accounted, as it represents the main contribution to the global warming potential.

Leceta et al. (2013) compared the environmental impact of food packaging made out of PP with chitosan-based one. The authors highlighted that the film manufacture stage is the category where chitosan-based films display the highest impact because of the not optimized process. On the contrary, the utilisation of chitosan films results in a highly positive impact as regard the end life scenario due to the composting possibility (Leceta et al., 2013).

Cellulose nanomaterials (CNs), obtained from wood fibers have recently gained considerable attention for the realisation of biocomposites capable of replacing fuel-based materials for packaging purposes. Indeed, the introduction of nano-sized additives to polymer matrices allows for the modulation of the physic-mechanical properties of the final material. In this respect, as underlined by Shatkin and Kim (2015), the environmental and safety aspects of CNs must be carefully evaluated to guarantee a safe commercial application. The authors proposed a life cycle risk assessment for these nanomaterials (NANO LCRA) with the aim of identifying potential exposure scenarios and evaluate the adequacy of the exisiting data and gaps that should be filled to decrease the uncertainty about CNs, highlighting the need for further studies to demonstrate their safety (Shatkin and Kim, 2015).

With regards to the drinking-water bottles, Gironi and Piemonte (2010) and Papong et al. (2014) conducted LCA analyses on PLA and PET bottles. Both works came to the conclusion that the use of PLA for production of the bottles in question produces benefits in terms of human health and environmental impact.

As mentioned above, one of the most important features of food packaging is shelf-life prolongation. In this respect, in recent years, many researchers have focused their attention upon active packaging. This concept has been established and developed with the purpose of efficiently preserve food for an extended period of time. Different technologies have been studied, such as gas scavengers, carbon dioxide emitters, moisture absorbers, antioxidant and/or antimicrobial systems (Tawakkal et al., 2014).

With the aim of identifying the most suitable and efficient method for food preservation, Pardo and Zufia (2012) compared four traditional and novel food preservation technologies: autoclave pasteurization, microwaves, high hydrostatic pressure and modified atmosphere packaging. New techniques resulted as less impacting in terms of energy demand and $\mathrm{CO}_{2}$ emissions, and nonthermal technologies required less water than thermal ones. Amongst the technological solutions investigated, modified atmosphere packaging was found to be the most sustainable solution for shelf life below 30 days (Pardo and Zufia, 2012).

The development of antimicrobial packaging is another emerging technique that allows for the suppression of the activity of targeted microorganisms. Both petroleum-based and bio-based 
polymers were evaluated as potential candidates for the manufacturing of antimicrobial packaging products, although the combination of biopolymers with antimicrobial attributes definitely represents a step forward to the reduction of food waste and environmental pollution. Indeed, a recent LCA study demonstrated that the application of an antimicrobial coating on Tetra Top ${ }^{\circledR}$ packaging for fresh milk could cause a reduction of $20-50 \%$ of milk waste that would result in a lower overall environmental impact for almost all the considered categories (Manfredi et al., 2015).

Other authors performed an LCA analysis by comparing traditional and antimicrobial packaging for fresh beef, with the purpose of identifying the breakeven point of the balance (Zhang et al., 2015). The results demonstrated that by using active packaging a breakeven point can be reached in all the assessed categories (global warming, fossil energy demand, acidification potential and eutrophication potential). Also, the authors concluded that the utilisation of a better-performing active packaging could contribute to reduce the beef losses at the retail of the European market by up to $147600 \mathrm{t} / \mathrm{y}$ (Zhang et al., 2015).

In conclusion, from the reviewed publications emerged that the substitution of traditional packaging with bio-based ones not always results in lower environmental impact. However, in the aforementioned contributions, mature and optimised materials and technologies were compared to emerging ones highlighting that, in the latter case, available data are still limited. Therefore, there is still room for improvement which emphasises upon the need for more studies to be carried out, so as to attempt providing designers, researchers and scientists, and other stakeholders with guidelines that may help increasing the eco-friendliness of their products.

\section{Materials and methods}

Life Cycle Assessment (LCA) has been significantly improved over the past three decades, so becoming more systematic and robust for both identification and quantification of the potential environmental impacts associated with a product's life-cycle (Jeswani et al., 2010). Currently, LCA is used for product/process selection, design and optimisation and can be coupled with simulation techniques and design tools to help companies become fully aware of the environmental consequences that their actions have both on- and off-site. This aspect contributes to making it an invaluable decision-support tool for stakeholders like researchers, manufacturers, policy-makers and company owners (Compagno et al., 2014; Ingrao et al., 2015a; Ingrao et al., 2016).

Two approaches to LCA have been developed in recent years with the aim of providing answers to different system-modelling questions, namely the attributional and consequential one. As Brander et al. (2009) state, failure to distinguish them can occur and would result in: the wrong method being applied; a mixture of the two approaches within a single assessment; or misinterpretation of results. In particular, the Attributional-LCA (A-LCA) provides information about the impacts of the processes used to produce, consume and dispose of a product. For contrast, the Consequential-LCA (CLCA) provides information about the consequences of changes in the level of output, consumption and disposal of a product, including effects both inside and outside the life-cycle of the product (Brander et al., 2009).

In particular, in the attributional approach inputs and outputs are attributed to the functional unit of the product system investigated, by linking and/or partitioning the unit processes of the system according to a normative rule. For contrast, the consequential approach considers activities in a 
product system that are linked with the extent that they are expected to change as a consequence of a change in demand for the functional unit (Ekvall et al., 2016).

This paper regards the evaluation of life-cycle environmental impacts for micro-level decision in the field of fresh-food packaging trays constituted by expanded-PLA. In the light of the above, the authors believed as proper to perform A-LCA, according to the ISO standards 14040 and 14044 (ISO, $2006 a, b)$.

The study is part of a research designed to investigate, from an environmental perspective, the lifecycle of fresh-food packaging trays made out of expanded polymers of both natural and synthetic origin. The aim is to understand if biodegradable polymers are valid alternatives to the synthetic ones, so contributing to identify and follow environmental sustainability pathways in the food packaging field.

The research has included the already-published studies of Ingrao et al. (2015 b,c) concerning the application of LCA and Carbon Footprint (CF) to trays of equal dimensions and production technologies but made out of expanded PS and PLA, respectively. In the study here presented, the PLA trays already tested by Ingrao et al. (2015c) were evaluated by performing a full LCA to make results comparable with Ingrao et al. (2015b). In particular, this paper reports upon both:

- assessment of the global environmental impact associated with the trays' life-cycle by considering more damage and impact categories with respect to Ingrao et al. (2015c); and

- comparison between expanded PS and PLA trays to document about the most sustainable option in environmental impact terms.

Therefore, this study can be considered to be complementary and essential for an even better understanding and appreciation of the entire research with regard to both methodologies applied and results obtained.

Moreover, in Section 2 the authors highlighted that none of the reviewed studies regarded environmental assessment of expanded-polymer trays for packaging of fresh foods. According to the authors, this emphasises well upon: the novelty of the study and, overall, of the research that it is part of; and, so, their contribution to the enhancement of both literature and knowledge of the sector, at a global level.

Finally, the results of this study will form the base for another one regarding the assessment of second-generation PLA granules, namely those produced by processing both wastes and wastewaters from starchy crop cultivation systems and processing plants.

\subsection{Goal and scope definition}

This study was aimed at performing A-LCA to identify environmental hotspots in the life-cycle of expanded PLA trays for fresh-food packaging, thereby representing a valid tool to identify more sustainable alternatives like, for instance, the utilisation of second-generation PLA granules. Furthermore, for enhancement of the scientific relevance and usefulness of this study and, overall, of the research, results from this paper will be compared with those from the Ingrao's et al. (2015b) A-LCA whose FU was $1 \mathrm{~kg}$ of equally-dimensioned PS-trays. In this regard, it should be observed that the single tray tested has a maximum capacity of $800 \mathrm{~m}^{3}$ but, as documented by Ingrao et al. (2015c), its weight changes depending upon the material utilised, so being equal to $8.98 \mathrm{~g}$ in the case of PS, whilst $11.36 \mathrm{~g}$ in that of PLA. This means that more PLA is required than PS during tray 
manufacturing. Moreover, the different tray's weight results in a different number of units per kg of trays: almost 111 for PS, whilst 88 for PLA (Ingrao et al., 2015c). Here, the FU and the system boundaries are those already defined by Ingrao et al. (2015 c), in order to be consistent with the goal of the study and make the latter comparable with Ingrao et al. (2015b). In fact, the FU is represented by $1 \mathrm{~kg}$ expanded-PLA trays whose dimensions have already been reported in Ingrao et al. (2015 c), and the system boundaries include the phases of manufacturing, delivering and disposal. In particular, according to Yates and Barlow (2013), the first phase included production and supply of the raw materials demanded for $1 \mathrm{~kg}$ tray manufacturing, starting from corn cultivation and harvesting. For contrast, the end-of-life was modelled considering that the tray is treated in an industrial compost plant.

Moreover, the use phase was excluded because, in line with the "Product-Category Rules (PCR) for Preparing an Environmental Product Declaration (EPD) for Food Contactable Plastic Containers" (Taiwan Plastics Industry Association, 2012), the environmental impact during this stage is likely insignificant.

Finally, the study is addressed to LCA practitioners, researchers, producers and company owners to inform them about the inventory flows and the environmental impacts that are associated with the system investigated. It was developed considering the interest that is increasingly being shown towards the environmental issues associated with the usage of such natural polymers in the packaging sector. Consequently, the authors believe that similar environmental studies would be desirable to trigger international debates upon both environmental criticalities and improvement potentials and production alternatives in the field of bio-polymers based packaging systems, like the trays under study.

\subsection{Life Cycle Inventory analysis}

All LCA-elaboration phases have important roles but, amongst them, the Life Cycle Inventory ( $\mathrm{LCl}$ ) analysis is acknowledged worldwide as the most significant one (Ingrao et al., 2015a). This is mainly because all the activities involved in the product's life-cycle must be analysed and modelled, and all data related to the environmental impacts must be compiled and calculated (Zhang et al., 2015). As clearly discussed by Lo Giudice et al. (2016), the LCl quantifies the usage of resources and materials and the consumption of fuels and energies, as well as the involved transportation associated with a product in its life-cycle.

In this context, since a specialised system was assessed in this study, priority was given to using sitespecific data (primary data) regarding the input material typologies and amounts utilised. Those data were provided by the firm that was positively involved in and so supported the study development: they were referred to 2015 though, according to the firm managers and technicians, can be considered as quite representative of the production trend. To collect those data and record other useful information, interviews with the firm technicians were made and check-lists were implemented for the case and filled in during production site investigations.

Additionally, as a standard practice in LCAs, secondary data were extrapolated from international databases of scientific importance and reliability. In particular, the processes used for representing the resources, materials and energies consumed (fuels included), as well as the road and maritime transport means utilised, were extrapolated from the Ecoinvent v.2.2 database (Ecoinvent, 2011) 
contained in SimaPro v.7.3.3 (Pre, 2006). In particular, the related modules of production and lifecycle currently present within it were accessed by the authors and used subsequently. Ecoinvent is considered worldwide as a reliable background data source: as Frischknecht and Rebitzer (2005) state, it accommodates most of the background materials and processes often required in LCA case-studies. As a matter of fact, by accessing it the authors found all the supportive data needed for both implementation and assessment of the model.

Finally, the reader is reminded to Ingrao et al. (2015c) for more information on the data used and the methodological choices made for the assessment.

\subsection{Life Cycle Impact Assessment}

The Life Cycle Assessment ( $\mathrm{LCIA}$ ) phase was carried out aggregating in a limited set of Impact Categories (ICs) all the output flows quantified in the LCl phase (De Benedetto and Klemes, 2009). To do so, the authors accessed and used the classification/characterisation framework provided by Impact 2002+ (Joillet et al., 2003). Then, the ICs were grouped into Damage Categories (DCs), namely environmental compartments suffering the damage caused by the product in its life-cycle. Hence, it is understood that the assessment was extended to the endpoint approach, so encompassing the phases of 'normalisation' and 'weighing'.

In particular, the mid-point approach was used to quantify the LCIA results in the form of specific characterisation values represented by equivalent indicators like, for instance, $\mathrm{kgCO}_{2 \text { eq }}$ for ' $\mathrm{Global}$ Warming', kgPM2.5.eq for 'Respiratory Inorganics', and $\mathrm{kgC}_{2} \mathrm{H}_{3} \mathrm{Cl}_{\text {eq }}$ for 'Carcinogens'.

As regards the end-point approach, the 'weighing' results were estimated by means of equivalent numerical parameters expressed as 'weighing points' or 'damage points' or 'eco-points' or, more simply, 'points'. Doing so allowed the authors to represent quantitatively the environmental impacts associated not only with the system investigated but, also, with all the included materials and processes, so as to highlight the most impacting ones. In particular, following Lo Giudice et al. (2016) the weighing points were obtained according to the IMPACT 2002+ framework, multiplying the dimensionless results from the 'normalisation' phase by $1 \mathrm{pt}$. The latter represents the factor (equal for all DCs and ICs) to convert results from the 'normalisation' to the 'weighing' phase. In the light of the above, it appears evident why the 'normalisation' and 'weighing' results are equal in absolute value terms (Lo Giudice et al., 2016).

\section{Results discussion and interpretation}

\subsection{Life Cycle Impact Assessment}

The study highlighted that the total damage is equal to $1.854 \mathrm{mpt}$ and is mainly due to: the production (for almost $49.7 \%$ ) and transport (for 25.43\%) of the PLA granules; the electricity consumption for their processing (for $12.2 \%$ ); and for $5.94 \%$ to the delivery of the produced trays. 
415 All the other processes and phases shown in Ingrao's et al. (2015c) Tables 4 and 5 account for the 416 remaining $6.73 \%$.

417 In this regard, a flow chart of the damages being originated from the materials and processes 418 encompassed by the system was depicted in Fig. 1. It is confirmed that PLA granule production is 419 the most impacting phase and other relevant contributions to the environmental impact associated 420 with the investigated system come from:

421 - the transportation of the granules to the tray manufacturing plant; and

422 - the electricity consumption for the processing of the granules into trays.

423 For greater understanding, Fig. 2 was reported to show single-score results per damage categories, 424 where the aforementioned total damage $(1.854 \mathrm{mpt})$ results from summing up the damages 425 associated with the materials, energies (electricity and heat) and processes depicted in the figure. 


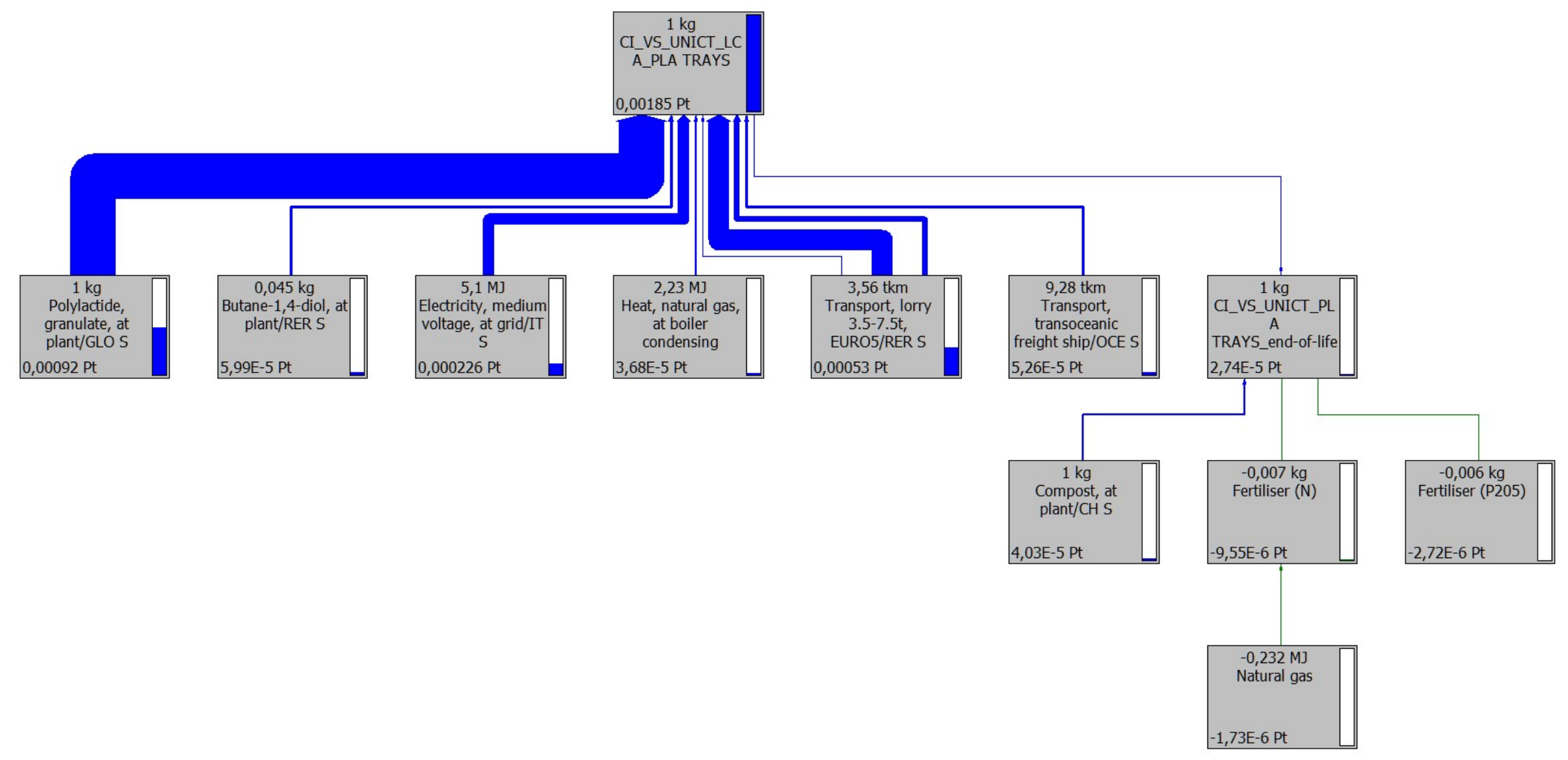




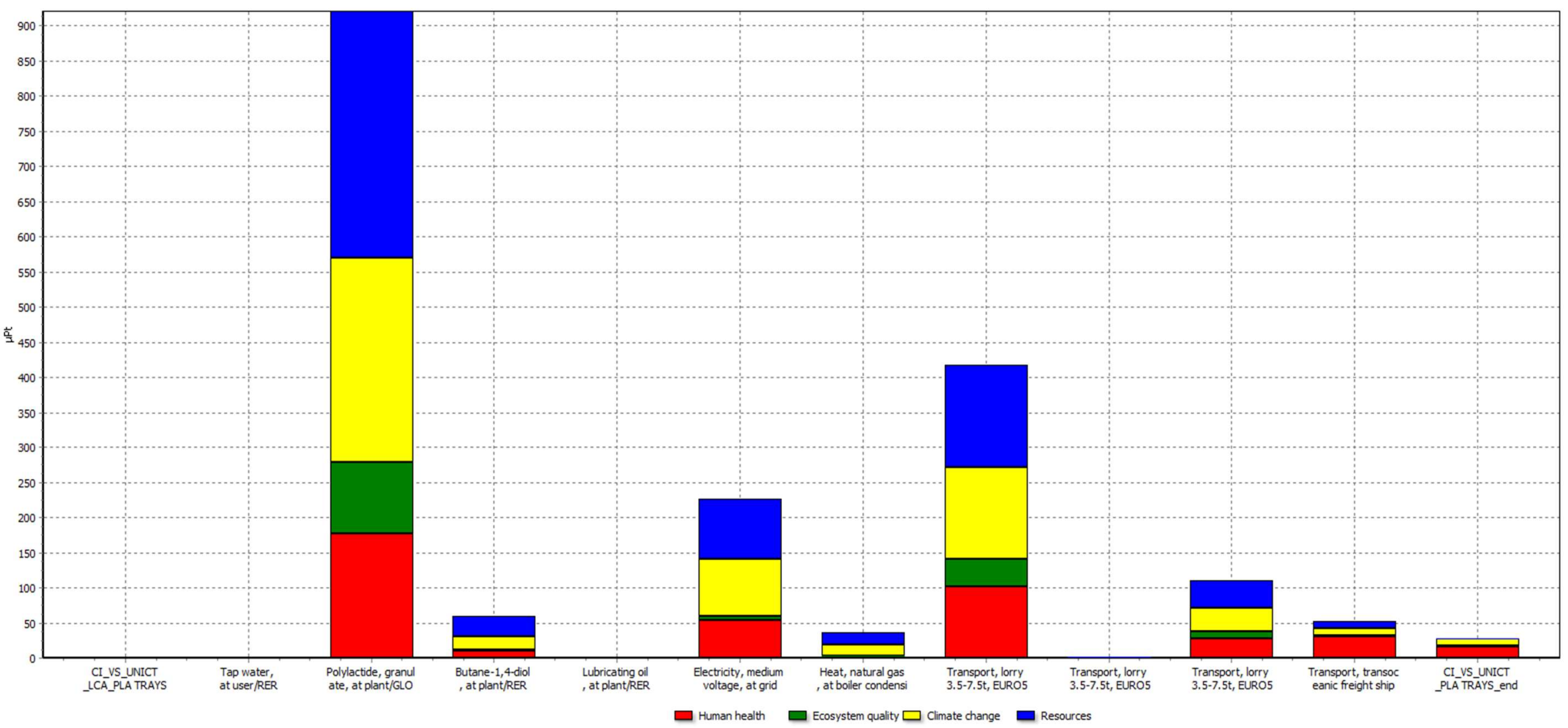

Fig.2. Single-score evaluation per damage category. Values are expressed as $\mu$ pt.kg tray $^{-1}$ 
Also, in Table 1 each DC was allocated the total weighing point and the weighing point associated with each single input considered. The total damage associated with the system investigated, namely $1.854 \mathrm{mpt}$, can be easily calculated by summing up each DC's total damage reported in the

440

441

442

443

444

445

446

447

448

449

450

451

452

453

454

455

456

457

458

459

460

461

462

463

464

465

466

467

468

first column of Table 1.

From both Fig. 2 and Table 1, there is evidence that:

- 'Resources' is the most impacted DC, followed by 'Climate Change', 'Human Health' and 'Ecosystem Quality';

- for all the DCs considered, the PLA-granule production phase is the most impacting one with values ranging from 1.01E-4 pt for 'Ecosystem Quality' to 3.51E-4 pt for 'Resources'. Therefore, its average contribution to each DC's total damage is around $51 \%$.

Table 1

Single-score evaluation per damage category. Values are expressed as points per kg of produced trays

\begin{tabular}{|c|c|c|c|c|c|c|}
\hline \multirow[b]{2}{*}{$\mathrm{DC}$} & \multirow[b]{2}{*}{ Total damage } & \multicolumn{3}{|c|}{ PLA granules } & \multirow{2}{*}{$\begin{array}{c}\text { Tray } \\
\text { delivery }\end{array}$} & \multirow{2}{*}{$\begin{array}{c}\text { Other } \\
\text { materials/processes }\end{array}$} \\
\hline & & Production & Transport & $\begin{array}{c}\text { Processing } \\
\text { (Electricity consumption) }\end{array}$ & & \\
\hline Resources & $6.80 \mathrm{E}-04$ & $3.51 E-04$ & $1.58 \mathrm{E}-04$ & $8.54 \mathrm{E}-05$ & 3.87E-05 & 4.80E-05 \\
\hline Climate change & 5.91E-04 & 2.91E-04 & $1.40 \mathrm{E}-04$ & $8.12 \mathrm{E}-05$ & $3.43 E-05$ & 4.36E-05 \\
\hline Human health & 4.20E-04 & 1.77E-04 & $1.33 \mathrm{E}-04$ & 5.37E-05 & $2.68 \mathrm{E}-05$ & 2.87E-05 \\
\hline Ecosystem quality & $1.63 \mathrm{E}-04$ & $1.01 \mathrm{E}-04$ & 4.07E-05 & $6.05 E-06$ & $1.03 E-05$ & 3.97E-06 \\
\hline
\end{tabular}

With particular regard to the ICs, from Table 2 there is evidence that those with the highest contributions to the total damage are: 'Non-renewable Energy' (NRE); 'Global Warming' (GW); 'Respiratory Inorganics' (RI); 'Land occupation' (LO); and 'Terrestrial Eco-Toxicity' (TET). These impact categories were reported in Table 2 in association with both damage points and characterisation values (mid- and end-point approach results).

\section{Table 2}

Weighing points and characterisation values for each of the impact categories causing the greatest damage

\begin{tabular}{cccc}
\hline IC & Weighing point & Characterisation value & Unit of measure \\
\hline Non-renewable Energy (NRE) & $6.80 \mathrm{E}-04$ & 103.36 & MJ primary \\
Global Warming (GW) & $5.91 \mathrm{E}-04$ & 5.85 & $\mathrm{kgCO}$ 2eq \\
Respiratory Inorganics (RI) & $3.88 \mathrm{E}-04$ & 0.004 & $\mathrm{kgPM}$ 2.5eq \\
Land Occupation (LO) & $9.56 \mathrm{E}-5$ & 1.2 & $\mathrm{~m}^{2}$ org.arable \\
Terrestrial Eco-Toxicity (TET) & $5.54 \mathrm{E}-5$ & 96 & $\mathrm{~kg}$ TEG soil \\
\hline
\end{tabular}

IC-results were compared with those identified in the document reporting upon "Product-Category Rules (PCR) for Preparing an Environmental Product Declaration (EPD) for Food Contactable Plastic Containers" (Taiwan Plastics Industry Association, 2012). In the document, 'Global warming', 'Acidification', 'Photochemical oxidant formation', 'Eutrophication', and 'Ozone depletion' were taken into account to define those PCRs. Apart from GW which can be considered as a function of NRE, differences were observed, because the other ICs considered in the present study (see Table 2) are strictly connected with the system investigated and, mostly, with: the production of the PLAgranules (from corn cultivation); and their transport to the tray manufacturing plant. 
Furthermore, from the LCIA they resulted to be the most significant ICs amongst those accounted by Impact $2002+$, as they most contributed to the total damage (1.854E-3 pt) associated with the system investigated. For contrast, the present LCA highlighted 'Ionizing Radiation', which is strictly interlinked with photochemical oxidation, and 'Ozone layer depletion' to be far less significant than those shown in Table 2, so as to be considered negligible. Their related contributions to the total damage were, indeed, equal to $0.241 \%$ and $0.00554 \%$. Additionally, Impact $2002+$ provides that 'Acidification' and 'Eutrophication' are mid-point indicators only and, so, are not included in the endpoint approach (Jolliet et al., 2003): hence, it was not possible to estimate their percent incidences to the system total-damage.

Therefore, the authors believe that the block of ICs considered in the present work (see Table 2) well models the system investigated and could be used as the starting base to define PCRs that are more specifically representative of the life-cycle of fresh-food packaging trays made out of expanded-PLA.

Entering into the merits of the single DC of Table 1, by performing the LCIA it was possible to highlight the most impacting resources consumed and substances emitted (in air, water and soil); in particular, it resulted that the damage affecting:

- 'Resources' is due for:

- $41.9 \%$, to the consumption of $1.07 \mathrm{~m}^{3} \cdot \mathrm{kg}_{\text {tray }}{ }^{-1}$ of 'Gas, natural, in ground' as a consequence of: the production (for $65.7 \%$ ) and transport (for $4.63 \%$ ) of the required PLA granules; the electricity demanded for their processing (for 7.59\%); and the tray distribution (for 1.15\%).

- $31.4 \%$, to the consumption of 'Oil, crude, in ground' in the amount of 708 g. $\mathrm{kg}_{\text {tray }}{ }^{-1}$, because of: the production (for $19.2 \%$ ) and transport (for $56.43 \%$ ) of the required PLA granules; the electricity demanded for their transformation into trays (for 15.6\%); as well as the tray delivery phase (for 13.8\%);

○ $14 \%$ to the consumption of 'Uranium, in ground' in the amount of 25.9 mg.kgtray ${ }^{-1}$, resulting from: the production (for 67.3\%) and transport (for 14.82\%) of the required PLA granules; as well as the electricity demanded for their processing (for 10.1\%);

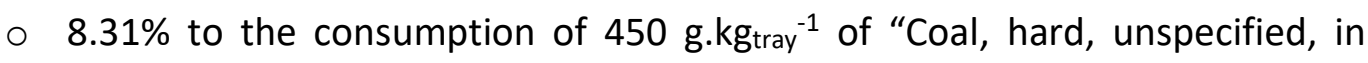
ground", coming from: the production (for 54.4\%) and transport (for $12.96 \%$ ) of the required PLA granules; as well as the electricity demanded for their processing (for 24.2\%);

- 'Climate Change' is due for $93.3 \%$ to the emission in air of fossil carbon dioxide in the amount of $5.45 \mathrm{~kg} \cdot \mathrm{kg}_{\text {tray }}{ }^{-1}$, as a result of: the production (for $48.5 \%$ ) and transport (for $24.76 \%$ ) of the PLA granules in the amount required for $1 \mathrm{~kg}$ tray production; the electricity demanded for their transformation into trays (for 14.3\%); as well as the tray delivery phase (for 6.02\%);

- 'Human Health' is caused for:

○ $40.2 \%$ by the emission in air of $13.4 \mathrm{~g}^{\mathrm{kg}} \mathrm{gtray}^{-1}$ of nitrogen oxides coming from: the production (for $34 \%$ ) and transport (for $40.2 \%$ ) of the required PLA 
granules; the electricity demanded for their transformation into trays (for $12.3 \%$ ); as well as the tray delivery phase (for $7.96 \%$ );

○ $23.5 \%$ by the emission in air of $1 \mathrm{~g} \mathrm{~kg}_{\text {tray }}{ }^{-1}$ of particulate matters with grain size less than 2.5 micron $\left(\mathrm{PM}_{<2.5}\right.$ ) and, in turn, by: the production (for $46.2 \%$ ) and transport (for $32.46 \%$ ) of the required PLA granules; the electricity demanded for their transformation into trays (for $10.3 \%$ ); as well as the tray delivery phase (for $7.46 \%$ );

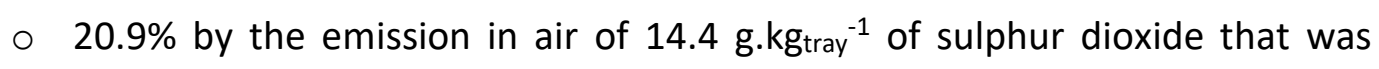
generated by: the production (for $46 \%$ ) and transport (for $24.05 \%$ ) of the required PLA granules; the electricity demanded for their transformation into trays (for 23.2\%); and the tray delivery phase (for $3.44 \%$ );

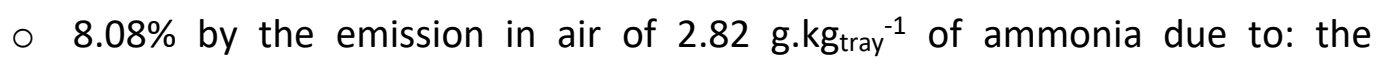
production (for $64.8 \%$ ) of the required PLA granules; and the tray composting (for 33\%);

- 'Ecosystem Quality' is caused for:

$\circ 48.7 \%$ by the occupation of $0.944 \mathrm{~m}^{2} \cdot \mathrm{y} \cdot \mathrm{kg}_{\text {tray }}{ }^{-1}$ of arable land invested for production of the starchy crop (i.e. maize) for production of the PLA granules;

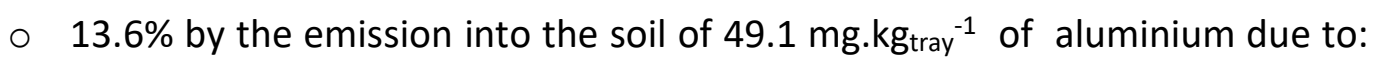
the production (for 68.2\%) and transportation (for 18.45\%) of the PLA granules utilised; the processing of PLA granules into trays (electricity production) for $5.58 \%$; and, finally, the tray delivery for $4.42 \%$.

The most impacting substances emitted and resources used discussed just above were summarised in Table 3 for each damage and impact category considered, and assigned the related: amount per $\mathrm{kg}$ of manufactured trays; characterisation value; weighing point; and percent contribution to the total damage (1.854E-3 pt) associated with the tray life-cycle. 
Most impacting substance and resources. LCIA results related to mid- and end-point approach

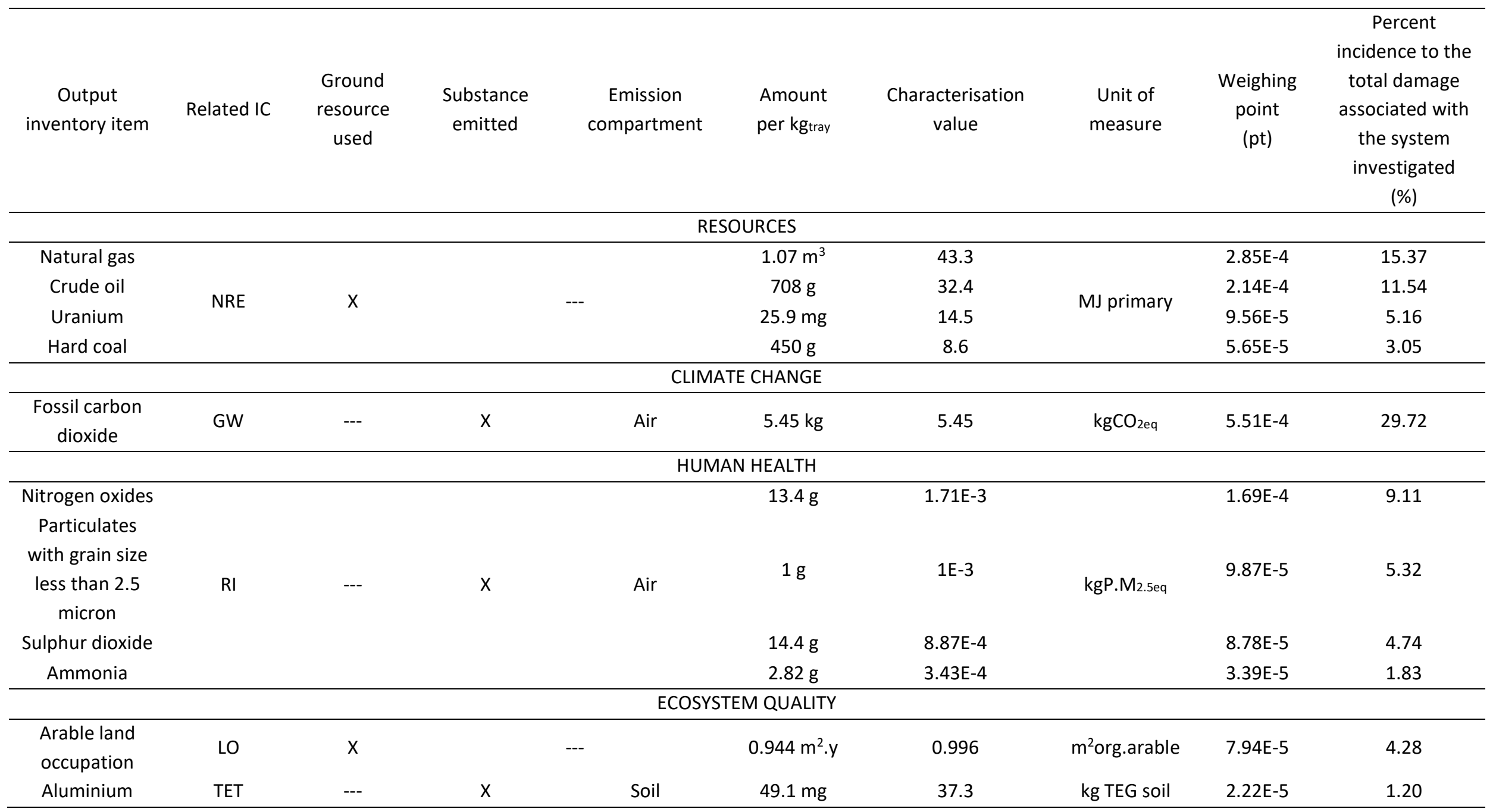


Based upon Table 3, there is evidence that those output substances and resources contributes for a total of $91.32 \%$ to the total damage ( $1.854 \mathrm{mpt}$ ). Therefore, according to the authors, they could be considered along with the ICs shown in Table 2 to identify the environmental indicators that best represent the system investigated. In particular, from Table 3 there is evidence that the emission of fossil carbon dioxide and the consumption of both natural gas and crude oil are the most critical environmental issues amongst those contained in the table itself.

\subsection{Sensitivity analysis}

As already mentioned, LCIA results from this paper were compared with those from Ingrao et al. (2015b) where $1 \mathrm{~kg}$ of equally-dimensioned trays was assessed by applying LCA. From the comparison conducted, it can be highlighted that the PLA trays are a bit more impacting (almost 16\%) than the PS ones: $1.854 \mathrm{mpt}$ vs. $1.560 \mathrm{mpt}$. In particular, the comparison was conducted at the mid-point approach level and the results drawn were shown in terms of damage points associated with: the life cycle of the trays (Fig. 3); and the DCs and ICs (Fig. 4). In both figures, values are expressed as pt.kg tray $^{-1}$.

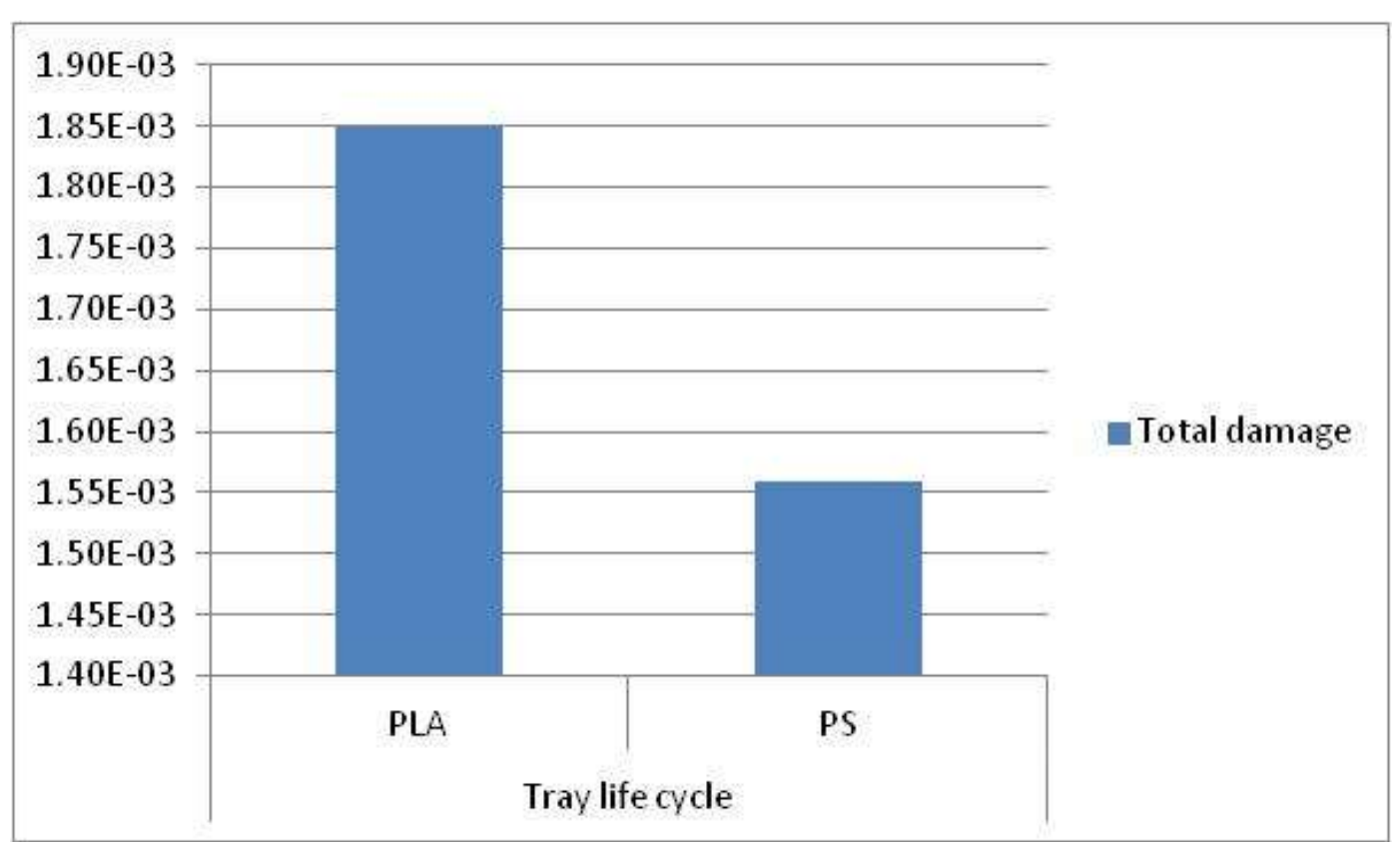

Fig. 3. A comparison of the (total) damages associated with the life cycles of PLA and PS trays. Values are expressed as pt.kgtray ${ }^{-1}$ 

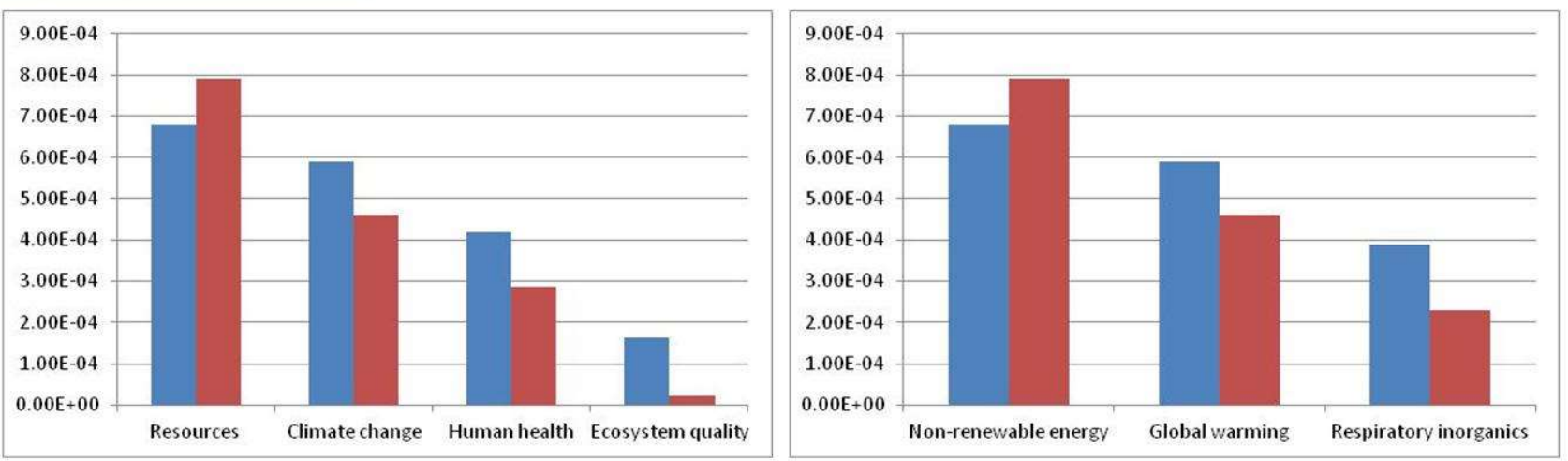

Fig. 4. A comparison of the damages associated with both DCs and ICs in the life cycles of PLA and PS trays. Values are expressed as pt.kg tray $^{-1}$

The PLA granule transport system is the step that most affects the total damage; in fact, the results show that the raw material transportation causes a total damage far higher than the one related to the PS granule: $0.472 \mathrm{mpt}$ vs. $0.0633 \mathrm{mpt}$. For contrast, based upon the findings from Ingrao et al. (2015b), the PLA granule production is less impacting than the one of the PS granules (0.921 mpt vs. $1.08 \mathrm{mpt}$ ). This is mainly because the latter, being a petroleum-based polymer, causes greater impacts in terms of non-renewable energy resource exploitation and Greenhouse Gas (GHG) emission. However, in this regard, it should be noticed that the impact upon 'Climate Change' (see Fig. 4) is greater in the PLA trays than in the PS ones because, as shown above, the transportation of the PLA granules to the tray manufacturing plant (from America to Italy) contributes for almost $25 \%$ to the damage associated with this DC.

Furthermore, from comparison of results there is evidence that, despite of the environmental gains associated with the avoided utilisation of chemical fertilisers resulting from compost administration in agreement with Ingrao et al. (2015c), the end-of-life of the PLA trays is more impacting than that of the PS ones: $2.74 \mathrm{E}-5$ pt vs. $1.18 \mathrm{E}-5$ pt (Ingrao et al., 2015b). This is mainly because, based upon the Ecoinvent models considered, the industrial compost plant resulted to be more impacting than the sanitary landfill, respectively considered for disposal of the PLA trays and the PS ones: 4.03E-5 pt (see Fig. 1) vs. 1.18E-5 pt (Ingrao et al., 2015b). Such a result should be attributed not only to the consumption of operational energies and fuels associated with the compost plant management but, mostly, to the emission of biogenic methane that comes from the organic matter decomposition and, as documented by Ingrao et al. (2015c), significantly impacts upon the 'Climate change' DC. In conclusion, it can be asserted that in the general context, though being produced from dedicated starchy crops and so with all the related criticalities, (first-generation) PLA granules are more environmentally sustainable than a synthetic polymer with the same food-packaging function, like PS. For contrast, the PLA granule supply still represents a system criticality: this is due to the fact that the cultivation of dedicated starchy-crops needs very large pieces of land and so it is often developed in countries (the Americas, for example) being very far from the majority of the processing plants. That is why the PLA-granule delivery phase currently involves long distances and different transport means, including in the examined case a freight ship, so causing significant impacts in terms of non-renewable energy resource exploitation and GHG emission. 
596 Therefore, this study, in line with the previous ones, remarked the significance of the transport 597 system to be considered and, at the same time, the need to search for alternative ways of PLA 598 granule production that avoid involving those large pieces of land for cultivation.

599 In this context, the authors intend to develop another study aimed at performing LCA and related 600 assessments in the field of second-generation PLA granules, namely those produced using wastes 601 and/or wastewaters from the cultivation systems and processing plants of starchy crops currently 602 used for food production.

603

\section{5. Monte Carlo Analysis}

605 This analysis was developed to create the probability distribution and so to determine the 606 uncertainty associated with the life cycle of $1 \mathrm{~kg}$ PLA trays for fresh-food packaging.

607 To perform the analysis, a 95\% confidence interval was considered and 1000 runs were made in 608 order to obtain a really good impression of the standard deviation and graphically represent the 609 probability distribution: the obtained results were shown in Fig. 5.

610 There is evidence that, based upon the standard of mean obtained (0.00337 pt), the uncertainty 611 rate in the total damage associated with the system investigated is quite acceptable, therewith 612 highlighting the reliability not only of the findings of the study but, also, of the primary and 613 secondary data collected and elaborated for the assessment. 


\section{Lognormal distribution of probability}

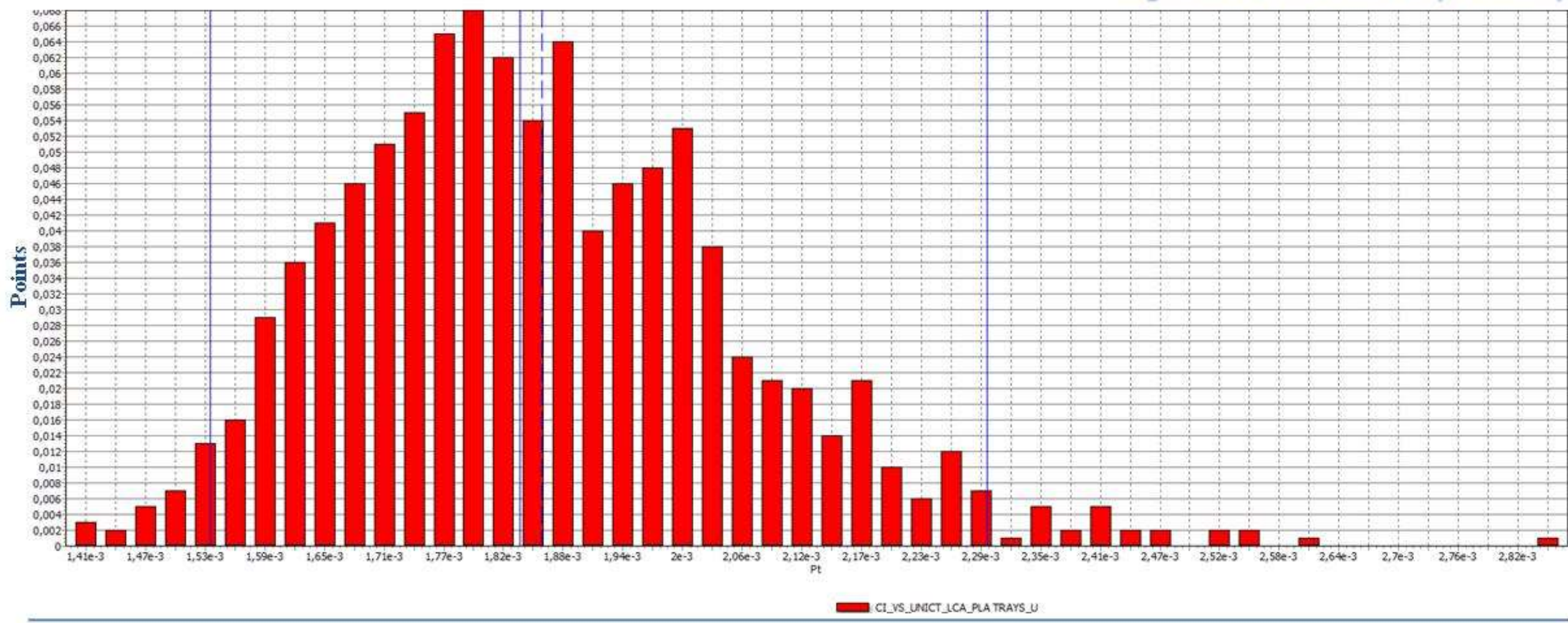
LCLA elaboration phase
Unit
Mean
Median
Standard deviation
Standard error of mean

\section{Single-score evaluation}

Pt

0.00186

0.00184

1.98E-04

0.00337

The Monte Carlo analysis, whose results was depicted above, is related to $1 \mathrm{~kg}$ PLA-trays life cycle and was performed in SimaPro using the Impact $2002+$ method. Additionally, for greater understanding it is specified that the values reported in the table are referred to the single score evaluation step. 


\section{Conclusions and future perspectives}

Food packaging systems are worldwide acknowledged to have the main function of containing and protecting foods during their shelf-lives. However, to perform this and other related functions a package generates several environmental impacts in its entire life-cycle. Therefore, it should be designed taking into account not only issues like cost, food shelf-life and safety, as well as userfriendliness, but also environmental sustainability. The latter is required to be addressed and improved to contribute, in turn, to the enhancement of both quality and functionality of cleaner packaging systems, so favouring their acceptance and demand at the global market scale. Therefore, methodologies and tools like LCA should be applied for estimation and identification of the major environmental impacts associated with a package in its life-cycle as the starting point to find more environmentally sustainable alternatives.

In this study, the authors attained the proposed goals and, indeed, performed an A-LCA of 1kg PLAtrays for fresh-food packaging applications, highlighting the related environmental criticalities and potential indicators. Additionally, they compared the obtained results with a previously-published paper (Ingrao et al., 2015b) regarding LCA of trays of the same dimensional characteristics but made out of PS.

Based upon the findings of the study, they concluded that the most impacting phase is represented by the production of the required amount of PLA granules, mainly due to the corn-cultivation phase. Other significant impacts come from the energy consumed in the processing of those granules but, mostly, from their transport to the tray manufacturing factory due to the huge distances travelled (from America to Italy) and the means utilised. In this regard, it should be highlighted that the transport issue causes high impacts in ways to worsen the life-cycle environmental sustainability of the PLA-trays, compared with the PS ones that were the object of the Ingrao's et al. (2015b) paper. Indeed, from the comparison carried out in this study between PLA and PS trays the authors documented that, overall, the former are more impacting than the latter, despite opposite results were found for the granule production phase.

Finally, in agreement with Ingrao et al. (2015c) the study, based upon its findings could contribute to the enrichment of the knowledge in the field and be used as the foundation to support ways to reconsider the feasibility of using (first-generation) PLA polymers for product manufacturing. Therefore, according to the authors, new research and policy frameworks should be designed and implemented for both development and promotion of more globally sustainable options with regard to the usage of materials and technologies. In this context, the results of this study will form the base for another one which will regard the assessment of second-generation PLA granules, namely those obtained using both wastes and wastewaters outlet from starchy-crop cultivation systems and processing plants. 


\section{References}

- Ahmed, J., Varshney, S.K., 2011. Polylactides-Chemistry, Properties and Green Packaging Technology: A Review. Int. J. Food Prop. 14, 37-58.

- Albrecht S., Brandstetter P., Beck T., Fullana-i-Palmer P., Grönman K., Baitz M., Deimling S., Sandilands J., Fischer M., 2013. Int. J. Life Cycle Assess. 18, 1549-1567.

- Bernstad Saraiva, A., Pacheco, E.B.A.V., Gomes, G.M., Visconte, L.L.Y., Bernardo, C.A., Simoes, C.L., Soares, A.G., 2016. Comparative lifecycle assessment of mango packaging made from a polyethylene/natural fiber-composite and from cardboard material. J. Clean. Prod. 139, 1168-1180.

- Brander, M., Tipper, R., Hutchison, C., Davis, G., 2009. Consequential and Attributional Approaches to LCA: a Guide to Policy Makers with Specific Reference to Greenhouse Gas LCA of Biofuels. Technical paper TP-090403-A. Extrapolated from: https://ecometrica.com/white-papers/consequential-and-attributional-approaches-to-Icaa-guide-to-policy-makers-with-specific-reference-to-greenhouse-gas-Ica-of-biofuels [Accessed: 11-Oct-2016].

- Castro-Aguirre E., Iñiguez-Franco F., Samsudin H., Fang X., Auras R. 2016. Poly(lactic acid)Mass production, processing, industrial applications, and end of life. Adv. Drug Deliver. Rev. 107, 333-366.

- Chen Y., Geever L.M., Killion J.A., Lyons J.G., Higginbotham C.L., Devine D.M., 2016. Review of Multifarious Applications of Poly (Lactic Acid). Polym-Plast. Technol. 55(10), 1057-1075.

- Compagno, L., Ingrao, C., Latora, A.G., Trapani, N., 2014. Life Cycle Assessment of CRT Lead Recovery Process. Int. J. Product Lifecycle Manage. 7, 201-214.

- De Benedetto, L., Klemes, J., 2009. The Environmental Performance Strategy Map: an integrated LCA approach to support the strategic decision-making process. J. Clean. Prod. 17, 900-906.

- Ecoinvent (2011). The Swiss Centre for Life Cycle Inventories. Ecoinvent v2.2.

- Ekvall, T., Azapagic, A., Finnveden, G., Rydberg, T., Weidema, B.P., Zamagni, A., 2016. Attributional and consequential LCA in the ILCD handbook. Int. J. Life Cycle Assess. 21, 293296.

- Frischknecht, R., Rebitzer, G., 2005. The ecoinvent database system: a comprehensive webbased LCA database. J. Clean. Prod. 13, 1337-1343.

- Genovese, L., Gigli M., Lotti, N., Gazzano, M., Siracusa, V., Munari, A., Dalla Rosa, M., 2014. Biodegradable long chain aliphatic polyesters containing ether-linkages: synthesis, solidstate, and barrier properties. Ind. Eng. Chem. Res. 53, 10965-10973.

- Gigli, M., Negroni, A., Soccio, M., Zanaroli, G., Lotti, N., Fava, F., Munari, A., 2013. Enzymatic hydrolysis studies on novel eco-friendly aliphatic thiocopolyesters. Polym. Degr. Stab. 98, 934-942.

- Gironi, F., Piemonte V., 2010. Life cycle assessment of polylactic acid and polyethylene terephthalate bottles for drinking water. Environmental Progress \& Sustainable Energy $30(3), 459-468$. 
- Grima, S., Bellon-Maurel, V., Feuilloley, P., Silvestre, F., 2002. Aerobic Biodegradation of Polymers in Solid-State Conditions: A Review of Environmental and Physicochemical Parameter Settings in Laboratory Simulations. J. Polym. Environ. 8, 183-195.

- Hermann, B.G., Blok, K., Patel, M.K., 2010. Twisting biomaterials around your little finger: environmental impacts of bio-based wrappings. Int. J. Life Cycle Assess. 15, 346-358.

- Ingrao, C., Matarazzo, A., Tricase, C., Clasadonte, M.T., Huisingh, D., 2015a. Life Cycle Assessment for highlighting environmental hotspots in Sicilian peach production systems. J. Clean. Prod. 92, 109-120.

- Ingrao, C., Lo Giudice, A., Bacenetti, J., Mousavi Khaneghah, A., de Souza Sant'Ana, A., Rana, R., Siracusa, V., 2015b. Foamy polystyrene trays for fresh-meat packaging: A life-cycle inventory data collection and environmental impact assessment. Food Res. Int. 76, 418-426.

- Ingrao, C., Tricase, C., Cholewa-Wójcik, A., Kawecka, A., Rana, R., Siracusa, V., 2015c. Polylactic acid trays for fresh-food packaging: A Carbon Footprint assessment. Sci. Total Environ. 537, 385-398.

- Ingrao, C., Scrucca, F., Tricase, C., Asdrubali, F., 2016. A comparative Life Cycle Assessment of external wall-compositions for cleaner construction solutions in buildings. J. Clean. Prod. 124, 283-298.

- ISO (International Organization for Standardization), 2006a. ISO 14040:2006 - Environmental management - Life cycle assessment - Principles and framework

- ISO (International Organization for Standardization), 2006b. ISO 14044: 2006 Environmental management - Life cycle assessment - Requirements and guidelines.

- Jambeck, J.R., Geyer, R., Wilcox, C., Siegler, T.R., Perryman, M., Andrady, A., Narayan, R., Lavender Law, K., 2015. Plastic waste imputs from land into the ocean. Science 347, 768-771.

- Jeswani, H.K., Azapagic, A., Schepelmann, P., Ritthoff, M., 2010. Options for broadening and deepening the LCA approaches. J. Clean. Prod. 18, 120-127.

- Joillet, O., Manuele, M., Raphael, C., Sébastian, H., Jérome, P., Gerald, R., Rosenbaum, R., 2003. IMPACT 2002+: a new life cycle impact assessment methodology. Int. J. Life Cycle Assess. 8, 324 - 330.

- $\quad$ Kale, G., Kijchavengkul, T., Auras, R., Rubino, M., Selke, S.E., Singh, S.P., 2007. Compostability of Bioplastic Packaging Materials: An Overview. Macromol. Biosci. 7, 255-277.

- Leceta, I., Guerrero, P., Cabezudo, S., de la Caba, K., 2013. Environmental assessment of chitosan-based films. J. Clean Prod. 41, 312-318.

- Licciardello, F., Cipri, L., Muratore, G., 2014. Influence of packaging on the quality maintenance of industrial bread by comparative shelf life testing. Food Packaging and Shelf Life 1, 19-24.

- Licciardello, F., Giannone, V., Del Nobile, M.A., Muratore, G., Summo, C., Giarnetti, M., Caponio, F., Paradiso, V.M., Pasqualone, A., 2017. Shelf life assessment of industrial durum wheat bread as a function of packaging system. Food Chem. 224, 181-190.

- Lo Giudice, A., Ingrao, C., Clasadonte, M.T., Tricase, C., Mbohwa, C., 2017. Life Cycle Assessment for highlighting environmental hotspots in the Sicilian traditional ceramic sector: the case of ornamental ceramic plates. J. Clean. Prod. 142, 225-239. 
- Madival, S., Auras, R., Singh, S.P., Narayan, R., 2009. Assessment of the environmental profile of PLA, PET and PS clamshell containers using LCA methodology. J. Clean Prod. 17, 1183-1194.

- Manfredi, M., Fantin, V., Vignali, G., Gavara, R., 2015. Environmental assessment of antimicrobial coatings for packaged fresh milk. 95, 291-300.

- Marine Litter Solutions, 2016. Available at: www.marinelittersolutions.com [Accessed: Dec 9-11, 2016].

- Messineo, A., Freni, G., Volpe, R., 2012. Collection of Thermal Energy Available from a Biogas Plant for Leachate Treatment in an Urban Landfill: A Sicilian Case Study. Sustainability 5, 3753-3767.

- Michaud, J.-C., Laura Farrant, L., Jan, O., 2010. Environmental benefits of recycling - 2010 update. http://www.wrap.org.uk/sites/files/wrap/Environmental benefits of recycling 2010 upd ate.3b174d59.8816.pdf [Accessed: Jan 27-29, 2017].

- Naturworks, 2016. Available at: www.natureworksllc.com [Accessed: Dec 9-11, 2016]

- Papong, S., Malakul, P., Trungkavashirakun, R., Wenunun P., Chom-in, T., Nithitanakul, M., Sarobol, E., 2014. Comparative assessment of the environmental profile of PLA and PET drinking water bottles from a life cycle perspective. J. Clean. Prod. 65, 539-550.

- Pardo, G., Zufia, J., 2012. Life cycle assessment of food-preservation technologies. J. Clean. Prod. 28, 198-207.

- Peelman, N., Ragaert, P., De Meulenauer, B., Adons, D., Peeters, R., Cardon, L., Van Impe, F., Devlieghere, F., 2013. Application of bioplastics for food packaging. Trends Food Sci. Tech. 32, 128-141.

- PlasticsEurope, Plastics - The Facts 2016, Brussels, Belgium, 2016. $<$ www.plasticseurope.org>

- Prè (2006). LCA software and Database Manual. Prè Consultants BV, Amersfoort, The Netherlands.

- $\quad$ Roes, A.L., Patel, M.K., 2011. Environmental assessment of a sugar cane bagasse food tray produced by roots biopack - results of a shortcut-life cycle assessment. J. Biobased Mater. Bioenergy 5, 140-152.

- Rossi, V., Cleeve-Edwards, N., Lundquist, L., Schenker, U., Dubois, C., Humbert, S., Jolliet, O., 2015. Life cycle assessment of end-of-life options for two biodegradable packaging materials: Sound application of the European waste hierarchy. J. Clean Prod. 86, 132-145.

- Shatkin, J.A., Kim, B., 2015. Cellulose nanomaterials: life cycle risk assessment, and environmental health and safety roadmap. Environ. Sci.: Nano 2, 477-499.

- Siracusa, V., Ingrao, C., Lo Giudice, A., Mbohwa, C., Dalla Rosa, M., 2014. Environmental assessment of a multilayer polymer bag for food packaging and preservation: an LCA approach. Food Res. Int. 62, 151-161.

- Siracusa, V., Rocculi, P., Romani, S., Dalla Rosa, M., 2008. Biodegradable polymers for food packaging: A review. Trends Food Sci. Tech. 19, 634-643.

- Suwanmanee, U., Varabuntoonvit, V., Chaiwutthinan, P., Tajan, M., Mungcharoen, T., Leejarkpai, T., 2013. Life cycle assessment of single use thermoform boxes made from 
polystyrene (PS), polylactic acid, (PLA), and PLA/starch: cradle to consumer gate. Int. J. Life Cycle Assess. 18, 401-417.

- Tabone, M.D., Cregg, J.J., Beckman, E.J., Landis, A.E., 2010. Sustainability Metrics: Life Cycle Assessment and Green Design in Polymers. Environ. Sci. Technol. 44, 8264-8269.

- Taiwan Plastics Industry Association, 2012. Product-Category Rules (PCR) for Preparing an Environmental Product Declaration (EPD) for Food Contactable Plastic Containers. Available at:

http://media.gednet.org/2012/12/ENG EPD PCR Food-Contactable-PlasticContainers final.pdf [Accessed: Jan 29-30, 2017].

- Tawakkal, I.S.M.A., Cran, M.J., Miltz, J., Bigger, S.W., 2014. A Review of Poly(Lactic Acid)Based Materials for Antimicrobial Packaging. J. Food Sci. 79(8), R1477-R1490.

- Verghese, K., Lockrey, S., Clune, S., Sivaraman, D., 2012. Life cycle assessment (LCA) of food and beverage packaging, in: Yam, K.L., Lee, D.S. (Eds.), Emerging Food Packaging Technologies: Principles and Practice. Woodhead Publishing, pp. 380-408.

- Vidal, R., Martinez, P., Mulet, E., Gonzalez, R., Lopez-Mesa, B., Fowler, P., Fang, J.M., 2007. Environmental assessment of biodegradable multilayer film derived from carbohydrate polymers. J. Pol. Environ. 15, 159-168.

- Wikström, F., Williams, H., Venkatesh, G., 2016. The influence of packaging attributes on recycling and food waste behaviour - An environmental comparison of two packaging alternatives. . Clean. Prod. 137, 895-902.

- Yates, M.R., Barlow, C.Y., 2013. Life cycle assessments of biodegradable, commercial biopolymers-A critical review. Resour. Conserv. Recy. 78, 54-66.

- Zabaniotou, A., Kassidi E., 2003. Life cycle assessment applied to egg packaging made from polystyrene and recycled paper. J. Clean. Prod. 11, 549-559.

- Zhang, H., Hortal, M., Dobon, A., Bermudez, J.M., Lara-Lledo, M., 2015. The Effect of Active Packaging on Minimizing Food Losses: Life Cycle Assessment (LCA) of Essential Oil Component-enabled Packaging for Fresh Beef. Packag. Technol. Sci., 28, 761-774.

- Zhang, Y., Luo, X., Buis, J.J., Sutherland, J.W., 2015. LCA-oriented semantic representation for the product life cycle. J. Clean. Prod. 86, 146-162.

\section{Acknowledgments}

- Dr. Carlo Ingrao has set up the whole study and has coordinated its development, in joint discussion with his co-authors, and has fully developed all parts related to application, discussion and conclusion of LCA.

- Dr. Matteo Gigli has worked upon the introduction and literature review sections.

- Prof. Valentina Siracusa has revised the final version of the paper before submission.

In this regard, Dr. Ingrao warmly thanks all the three co-authors for their multiple contributions in the development of the study and the writing of this document.

Moreover, Dr. Ingrao, also on behalf of his co-authors, thanks the tray manufacturing firm for being positively involved in this merely scientific collaboration and, so, for actively supporting this study development. 
822 Finally, the team of authors thanks: the experts who through their in-depth, valuable review work 823 have contributed to improvement and upgrade of the paper; and the editors, Prof. Rodrigo Lozano 824 and Prof. Cecilia Maria Villas Bôas de Almeida, for so professionally and kindly handling the paper 825 submission. 